\title{
Inonotus obliquus-derived polysaccharide inhibits the migration and invasion of human non-small cell lung carcinoma cells via suppression of MMP-2 and MMP-9
}

\author{
KI RIM LEE* , JONG SEOK LEE* , JEONG EUN SONG, SUK JIN HA and EOCK KEE HONG \\ Department of Bioengineering and Technology, Kangwon National University, \\ Chuncheon, Gangwon-do 200-701, Republic of Korea
}

Received June 15, 2014; Accepted August 12, 2014

DOI: $10.3892 /$ ijo.2014.2685

\begin{abstract}
Polysaccharides isolated from the fruiting body of Inonotus obliquus (PFIO) are known to possess various pharmacological properties including antitumor activity. However, the anti-metastatic effect and its underlying mechanistic signaling pathway involved these polysaccharides in human non-small cell lung carcinoma remain unknown. The present study therefore aimed to determine the anti-metastatic potential and signaling pathways of PFIO in the highly metastatic A549 cells. We found that PFIO suppressed the migration and invasive ability of A549 cells while decreasing the expression levels and activity of matrix metalloproteinase (MMP)-2 and MMP-9. Furthermore, PFIO decreased the phosphorylation levels of mitogen-activated protein kinases (MAPKs) and phosphoinositide 3-kinase (PI3K)/protein kinase B (AKT) as well as the expression level of COX-2, and inhibited the nuclear translocation of nuclear factor $\kappa \mathrm{B}(\mathrm{NF}-\kappa \mathrm{B})$ in $\mathrm{A} 549$ cells. These results suggested that PFIO could suppress the invasion and migration of human lung carcinoma by reducing the expression levels and activity of MMP-2 and MMP-9 via suppression of MAPKs, PI3K/AKT, and NF- $\mathrm{B}$ signaling pathways.
\end{abstract}

Correspondence to: Dr Eock Kee Hong, Department of Bioengineering and Technology, Kangwon National University, 192-1 Hyoja-2-dong, Chuncheon, Gangwon-do 200-701, Republic of Korea E-mail: ekhong@kangwon.ac.kr

*Contributed equally

Abbreviations: ECM, extracellular matrix; ERK, extracellular signalregulated protein kinase; JNK, c-Jun N-terminal kinase; MAPK, mitogen-activated protein kinase; MMP, matrix metalloproteinase; TIMP, tissue inhibitor of metalloproteinase; NF- $\kappa B$, nuclear factor $\kappa B$; COX, cyclooxygenase; AKT, protein kinase B; PI3K, phosphoinositide 3-kinase

Key words: Inonotus obliquus, lung, A549, migration, invasion, matrix metalloproteinase, nuclear factor $\kappa \mathrm{B}$

\section{Introduction}

Lung cancer is one of the most common malignancies worldwide. The high mortality rate is attributed to its early metastasis, especially in cases of non-small cell lung carcinoma (NSCLC) (1-3). Metastasis involves a series of complex processes in which tumor cells invade other organs, requiring the coordination of several signaling pathways that allow the detachment of tumor cells, their mobility, degradation of the extracellular matrix (ECM), invasion, migration, adhesion to endothelial cells, and reestablishment of growth at a distant site $(4,5)$. ECM and matrix metalloproteinases (MMPs) in humans have been identified as key factors involved in these processes. The degradation of basement membrane and stromal ECM is a crucial step for tumor invasion and metastasis (6). The MMP family of human zinc-dependent endopeptidases is responsible for degradation of the ECM components such as collagen, proteoglycan, fibronectin, elastin, and laminin (7). Of those, gelatinases, MMP-2, and MMP-9 are known to play a critical role in the degradation of native collagen types IV and V (8). MMP-2 is activated on the cell surface by a multimeric complex consisting of MMP-2, membrane type-1 MMP, and tissue inhibitor of metalloproteinase-2 (TIMP-2), whereas TIMP-1 is known as a specific inhibitor of MMP-9 (9). The expression of MMP genes is primarily regulated through transcriptional factors such as activator protein-1 (AP-1) and/or nuclear factor $\kappa$ B $(\mathrm{NF}-\kappa \mathrm{B})$ via mitogen-activated protein kinases (MAPKs) or phosphoinositide 3-kinase (PI3K)/protein kinase B (AKT) pathways (10-12). Several studies on cyclooxygenase (COX)-2 in cancers indicated that this enzyme stimulated tumor growth, invasion and metastasis in association with MMPs (13). COX-2 is an inducible isoform of cyclooxygenase that participates in pro-inflammatory responses to certain stimuli such as mitogens, cytokines and growth factors $(14,15)$. These studies revealed that MMPs and their regulatory pathways might be promising targets for anti-metastatic and chemotherapeutic therapy.

Mushrooms have been used to treat various diseases including tumors. Inonotus obliquus, a traditional medicinal mushroom, has been widely used to promote health and longevity in humans. Many studies have suggested that poly- 
saccharides from basidiomycetes mushrooms exhibited highly beneficial therapeutic effects including: i) direct antitumor activity against various tumors, ii) synergistic antitumor activity in combination with chemotherapy, and iii) preventive effects on tumor metastasis (16-20). However, the anti-metastatic effect and its underlying mechanistic signaling pathways of polysaccharides from fruit body of Inonotus obliquus (PFIO) in human NSCLC remain unknown. Therefore, the present study aimed to investigate the anti-metastatic effects and potential signaling pathways of PFIO in the highly metastatic human NSCLC A549 cells in vitro.

\section{Materials and methods}

Preparation of polysaccharides from Inonotus obliquus. Dried fruiting bodies of Inonotus obliquus were purchased from a local market and ground in a blender. Milled mushroom $(20 \mathrm{~g})$ was extracted with distilled water $(600 \mathrm{ml})$ at $121^{\circ} \mathrm{C}$ for $2 \mathrm{~h}$. Extracts were centrifuged at 5,000 rpm for $20 \mathrm{~min}$, filtered through $0.45-\mu \mathrm{m}$ Whatman \#4 filter paper to remove insoluble matter and freeze-dried. Polysaccharides were precipitated from resuspended extracts by ethanol precipitation via the addition of $75 \%(\mathrm{v} / \mathrm{v})$ aqueous ethanol, collected by filtration through $0.45-\mu \mathrm{m}$ Whatman filter paper, resuspended and dialyzed against distilled water for 5 days to remove low-molecular weight compounds $(18,19)$.

Materials. Fetal bovine serum (FBS), penicillin G, streptomycin and RPMI-1640 media were obtained from Gibco (Grand Island, NY, USA). 3-(4,5-Dimethylthiazol-2-yl)-2,5diphenyltetrazolium bromide (MTT), and isopropyl alcohol were purchased from Sigma Chemical Co. (St. Louis, MO, USA). $\beta$-actin monoclonal antibody (mAb), extracellular signal-regulated kinase (ERK) Ab, phospho-ERK Ab, stress-activated protein kinase/c-Jun $\mathrm{N}$-terminal kinase (SAPK/JNK) Ab, phospho-SAPK/JNK Ab, p38 MAPK Ab, phospho-p38 MAPK Ab, AKT Ab, phospho-AKT Ab, COX-2 Ab, MMP-2 Ab, MMP-9 Ab, TIMP-2 Ab, and NF-кB p50 Ab were purchased from Cell Signaling Technology (Boston, MA, USA), Santa Cruz Biotechnology (Santa Cruz, CA, USA), or BD Bioscience (San Diego, CA, USA). All other chemicals used were of analytical grade.

Cell culture. Human A549 NSCLC cell line was obtained from the Korea Cell Line Bank (Seoul, Korea). A549 cells were cultured in RPMI-1640 supplemented with $10 \%$ heat-inactivated $\mathrm{FBS}, 100 \mathrm{U} / \mathrm{ml}$ penicillin and $100 \mu \mathrm{g} / \mathrm{ml}$ streptomycin. Cells were maintained at $37^{\circ} \mathrm{C}$ in a humidified $5 \% \mathrm{CO}_{2}$ incubator.

Cell viability. A549 cells were seeded into 12-well cell culture plates and incubated for $24 \mathrm{~h}$. After various treatments, cell viability was evaluated using the MTT assay, which is based on the reduction of a tetrazolium salt by mitochondrial dehydrogenase in viable cells. After treatments, $500 \mu \mathrm{g} / \mathrm{ml}$ MTT solution was added to each well and incubated for $3 \mathrm{~h}$ at $37^{\circ} \mathrm{C}$. The formazan crystals in each well were dissolved in isopropyl alcohol and absorbance was measured at $595 \mathrm{~nm}$ using a microplate reader (Bio-Rad Laboratories, Hercules, CA, USA).
Flow cytometry. Apoptotic index was determined using a fluorescein isothiocyanate (FITC)-labeled Annexin V/ propidium iodide (PI) apoptosis detection kit (Molecular Probes, Eugene, OR, USA) according to the manufacturer's instructions. Briefly, cells were harvested, washed with phosphate-buffered saline (PBS) and centrifuged to collect the cell pellet. The number of cells was adjusted to $1 \times 10^{6}$ cells $/ \mathrm{ml}$. Then, the cells were resuspended in binding buffer [10 mM HEPES, $140 \mathrm{mM} \mathrm{NaCl}$, and $2.5 \mathrm{mM} \mathrm{CaCl}{ }_{2}$ (pH 7.4)] and stained with FITC-labeled Annexin V/PI at room temperature for $15 \mathrm{~min}$ in light-protected conditions. Flow cytometric analysis was performed using a FACSCalibur flow cytometer (Becton-Dickinson, Mountain View, CA, USA). The percentage of apoptotic cells was calculated using CellQuest software (Becton-Dickinson). Cells in the early phase of apoptosis were Annexin V-positive and PI-negative, whereas those in the late phase of apoptosis were positive for both Annexin V and PI. The apoptotic index (\%) was calculated as the sum of cells in the early and late phases of apoptosis divided by the total number of events.

Wound healing assay. Wound healing assay was performed as previously described with some modifications (21). Briefly, A549 cells were cultured to confluence in 6-well cell culture plates for $24 \mathrm{~h}$ in serum-free medium. The medium was replaced with serum-containing medium followed by the addition of PFIO at various concentrations $(25,50$ and $100 \mu \mathrm{g} / \mathrm{ml}$ ) and the cell monolayers were disrupted by scraping them with a $100-\mu 1$ micropipette tip. At the indicated time points $(0,24$ and $48 \mathrm{~h})$ after scraping, the cells were washed twice with PBS (pH 7.4) and photographed using an optical microscope at $\mathrm{x} 40$ magnification.

In vitro migration and invasion assay. The migration of A549 cells was also measured by chemotactic directional migration using a 6-well transwell insert. The $8-\mu \mathrm{m}$ pore filters (Corning, NY, USA) were coated with gelatin (Sigma). A549 cells $\left(1 \times 10^{6}\right.$ cells $\left./ \mathrm{ml}\right)$ were seeded in the upper chambers with or without PFIO (50 and $100 \mu \mathrm{g} / \mathrm{ml}$ ) and allowed to undergo migration for $24 \mathrm{~h}$. Non-migrated cells in the upper chambers were then removed with a cotton swab. The filters were stained with $2 \%$ crystal violet. Migrated cells adhered to the underside of the filters were counted and photographed using an optical microscope at $\mathrm{x} 40$ magnification. The invasion of A549 cells was measured using Matrigel-coated transwell cell culture chambers ( $8-\mu \mathrm{m}$ pore size) as previously described. After the cells were cultured for $24 \mathrm{~h}$ in serum-free DMEM, they were collected, resuspended in serum-free medium, seeded in the upper chambers of the transwell inserts $\left(1 \times 10^{6} \mathrm{cells} / \mathrm{ml}\right)$, and incubated with or without PFIO (50 or $100 \mu \mathrm{g} / \mathrm{ml})$. DMEM containing $10 \%$ FBS was placed in the lower chamber. All the cells in each treatment group were incubated for $24 \mathrm{~h}$ at $37^{\circ} \mathrm{C}$ in a humidified atmosphere with $95 \%$ air and $5 \% \mathrm{CO}_{2}$. The non-invasive cells that remained in the upper chambers were removed by wiping with a cotton swab, and the invasive cells were fixed with $4 \%$ formaldehyde in PBS and stained with $2 \%$ crystal violet in $2 \%$ ethanol. The invasive cells that penetrated through the Matrigel coating and present on the lower surface of the filters were counted and photographed using an optical microscope at $\mathrm{x} 40$ magnification. 
Zymography analysis. Sodium dodecyl sulfate-polyacrylamide gel electrophoresis (SDS-PAGE) substrate-embedded enzymography (zymography) analysis was used to identify enzyme activities with collagenase and gelatinase (22). Briefly, the supernatant collected from cell culture was resolved in $10 \%$ SDS-PAGE gels, which were prepared by the incorporation of gelatin $(1 \mathrm{mg} / \mathrm{ml})$ before casting. After electrophoresis, the gels were washed twice for $30 \mathrm{~min}$ in $2.5 \%$ Triton X-100 with shaking. They were then incubated at $37^{\circ} \mathrm{C}$ for $24-72 \mathrm{~h}$ in reaction buffer containing $50 \mathrm{mM}$ Tris- $\mathrm{HCl}(\mathrm{pH} 7.6), 10 \mathrm{mM}$ $\mathrm{CaCl}_{2}, 150 \mathrm{mM} \mathrm{NaCl}$, and $20 \%$ sodium azide, followed by staining with $0.25 \%$ Coomassie brilliant blue G-250 in $50 \%$ methanol and $10 \%$ acetic acid for $1-2 \mathrm{~h}$. The completely stained gels were appropriately destained with $40 \%$ methanol and $10 \%$ acetic acid. The enzyme activity was evident as clear (unstained) regions against the dark background.

Western blot analysis. Treated cells were washed in 1X PBS and lysed in lysis buffer [10 mM Tris- $\mathrm{HCl}(\mathrm{pH} 7.5), 10 \mathrm{mM}$ $\mathrm{NaH}_{2} \mathrm{PO}_{4} / \mathrm{NaHPO}_{4}(\mathrm{pH} 7.5), 130 \mathrm{mM} \mathrm{NaCl}, 1 \%$ Triton X-100, $10 \mathrm{mM} \mathrm{NaPPi}, 1 \mathrm{mM}$ phenylmethylsulphonyl fluoride and $2 \mu \mathrm{g} / \mathrm{ml}$ pepstatin A] for $30 \mathrm{~min}$ on ice. The lysates were centrifuged at $15,600 \mathrm{rpm}$ for $30 \mathrm{~min}$ at $4^{\circ} \mathrm{C}$. The supernatant was collected and its protein content was measured using a Bio-Rad protein assay kit before analysis. The total or fractionated protein samples were loaded and separated using SDS-PAGE and transferred to nitrocellulose membranes (Immun-Blot NC membrane, $0.2 \mu \mathrm{m}$; Bio-Rad). Membranes were blocked with $1.5 \%$ skim milk in $1 \mathrm{X}$ Tris-buffered saline (TBS) containing $0.1 \%$ Tween-20 for $1 \mathrm{~h}$ and incubated with primary antibodies at $4^{\circ} \mathrm{C}$ overnight. Finally, the membranes were treated with horseradish peroxidase -linked secondary antibodies for $1 \mathrm{~h}$ at room temperature. TBS washing was performed after each antibody binding reaction. The expression of each protein was detected using an enhanced chemiluminescence kit (Millipore Co., Billerica, MA, USA).

Nuclear protein extraction. Nuclear extracts were prepared by lysing nuclei in high-salt buffer supplemented with protease and phosphatase inhibitors using a nuclear extraction kit (Panomics Inc., Fremont, CA, USA) according to the manufacturer's protocol. Protein concentrations were quantified using the Bio-Rad protein assay.

Statistical analysis. Data are expressed as mean \pm standard error values, and results were obtained from at least three independent experiments performed in triplicates. All data were analyzed using Student's t-test to evaluate significant differences. A p-value of $<0.05$ was considered statistically significant.

\section{Results}

Effect of PFIO on A549 cell viability. To investigate the cytotoxicity of PFIO, A549 cells were treated with PFIO at various concentrations ranging from 0 to $1,000 \mu \mathrm{g} / \mathrm{ml}$ for $24 \mathrm{~h}$ and cell viability was determined by the MTT assay. We found that $0-200 \mu \mathrm{g} / \mathrm{ml}$ of PFIO did not significantly affect A549 cell growth (Fig. 1A). In these experiments, cell viability was $82 \%$ at $200 \mu \mathrm{g} / \mathrm{ml}$. Results of the FITC-labeled Annexin V and PI

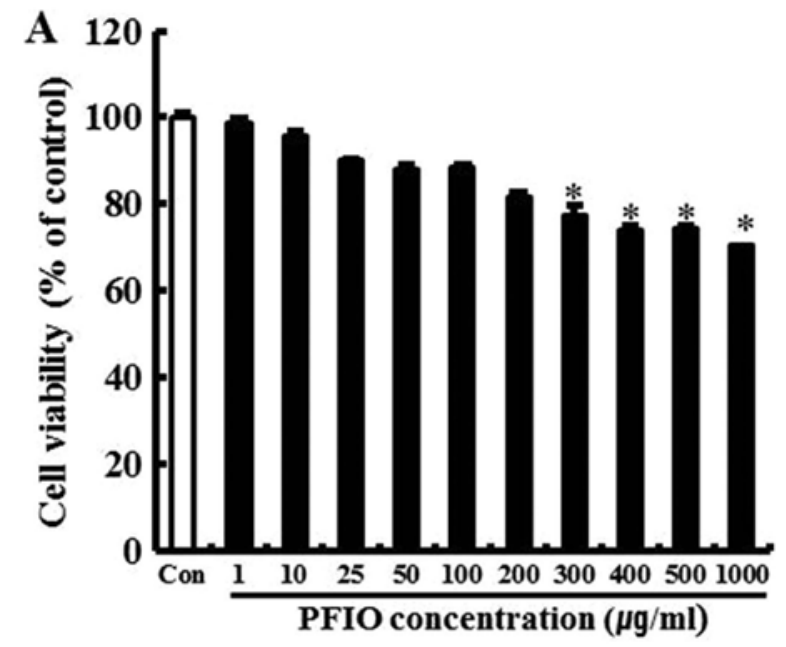

B
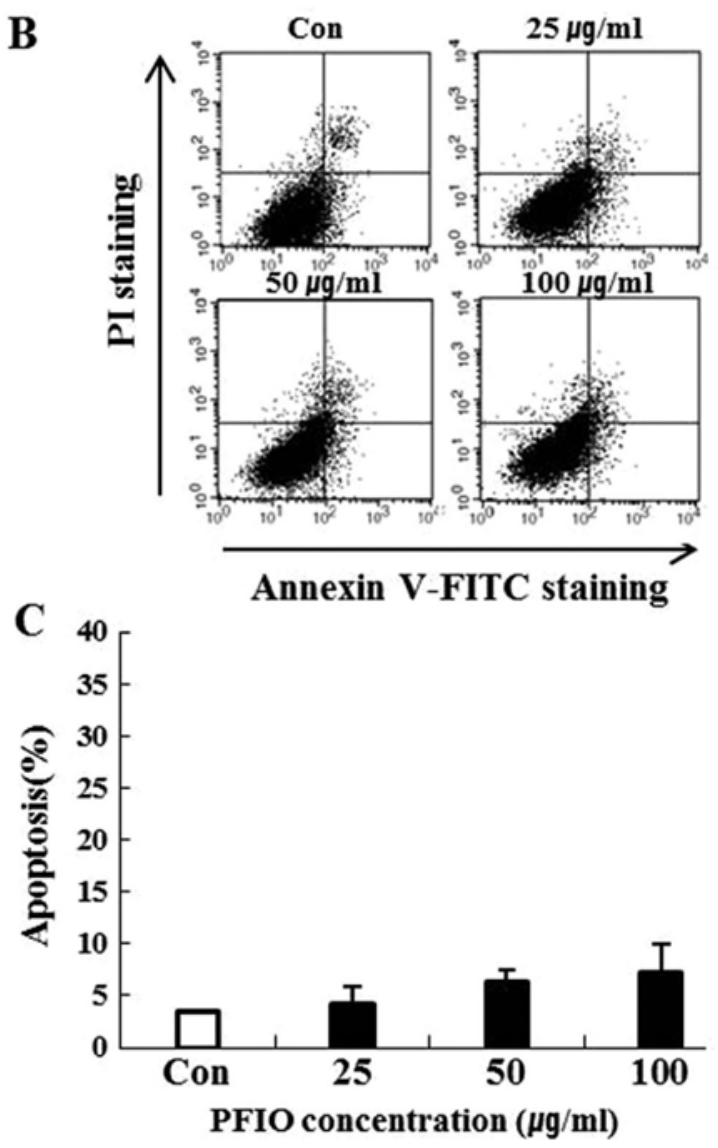

Figure 1. Effect of PFIO on A549 cell viability and apoptosis. (A) Viability of A549 cells treated with various PFIO concentrations $(0-1000 \mu \mathrm{g} / \mathrm{ml})$ for $24 \mathrm{~h}$ via MTT assay. (B and C) Flow cytometric analysis of A549 cells treated with various PFIO concentrations $(0-100 \mu \mathrm{g} / \mathrm{ml})$ for $24 \mathrm{~h}$. Data are presented as the mean $\pm \mathrm{SE}$ of three independent experiments. ${ }^{*} \mathrm{p}<0.05$ indicates a significant difference from controls.

double-staining experiments revealed that PFIO at $100 \mu \mathrm{g} / \mathrm{ml}$ induced apoptosis in $7.1 \%$ of the cells (Fig. 1B and C), whereas concentrations ranging from 0 to $100 \mu \mathrm{g} / \mathrm{ml}$ of PFIO did not induce cell death and apoptosis in the highly metastatic A549 cell line. This concentration range was then applied in all subsequent experiments.

Effects of PFIO on the motility of A549 cells. The effects of PFIO on A549 cell migration was determined using the 
A

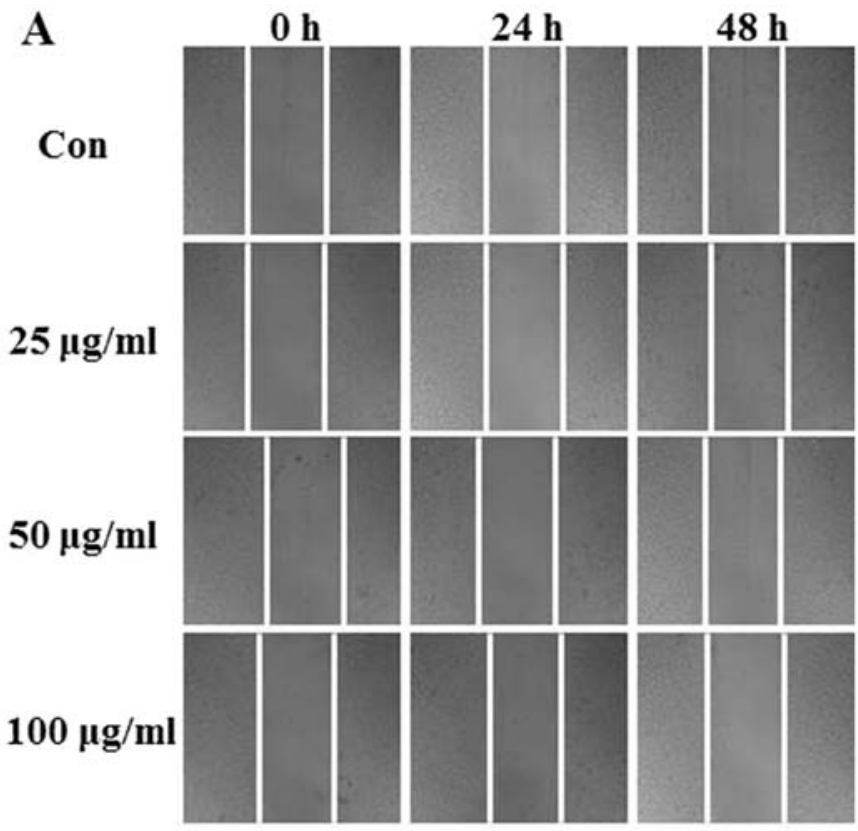

B

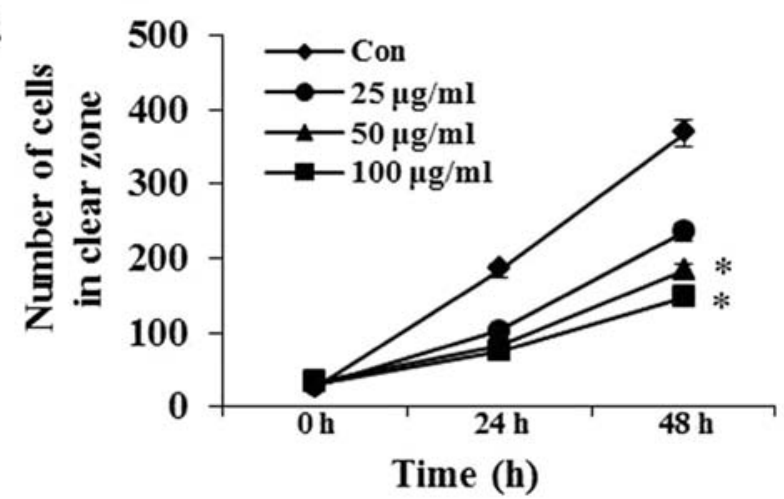

Figure 2. Effects of PFIO on the motility of the A549 cells. (A) Cell mobility was determined by the wound healing assay when monolayers of A549 cells were treated with various PFIO concentrations $(0,25,50$ and $100 \mu \mathrm{g} / \mathrm{ml})$ for 24 and $48 \mathrm{~h}$. (B) Quantitative assessment of the cell number in the clear zones of the wound healing assay. Data are presented as the mean $\pm \mathrm{SE}$ of three independent experiments. " $p<0.05$ indicates a significant difference from controls.

wound-healing assay in which cells were stimulated to migrate by physical wounding. As shown in Fig. 2A, when cells were treated with PBS for 24 and $48 \mathrm{~h}$, an apparent and gradual increase of cells in the denuded zone was observed under light microscopy. A549 cells treated with 25,50 or $100 \mu \mathrm{g} / \mathrm{ml}$ of PFIO displayed a reduced ability to migrate and fill the wounded area compared with untreated cells. The quantitative data in Fig. 2B revealed that PFIO could significantly inhibit the migration of A549 cells.

Effect of PFIO on A549 cell migration and invasion. To further evaluate the anti-metastatic activity of PFIO, we assessed the inhibition of A549 migration and invasion by PFIO using transwell assay with polycarbonate filters (pore size, $8 \mu \mathrm{m}$ ) pre-coated with gelatin or Matrigel. Our results indicated that A549 cells were observed moving from the upper to the lower chamber in the absence of PFIO (control group), suggesting that A549 cells could migrate across a transwell insert precoated with gelatin. PFIO at 50 and $100 \mu \mathrm{g} / \mathrm{ml}$ significantly

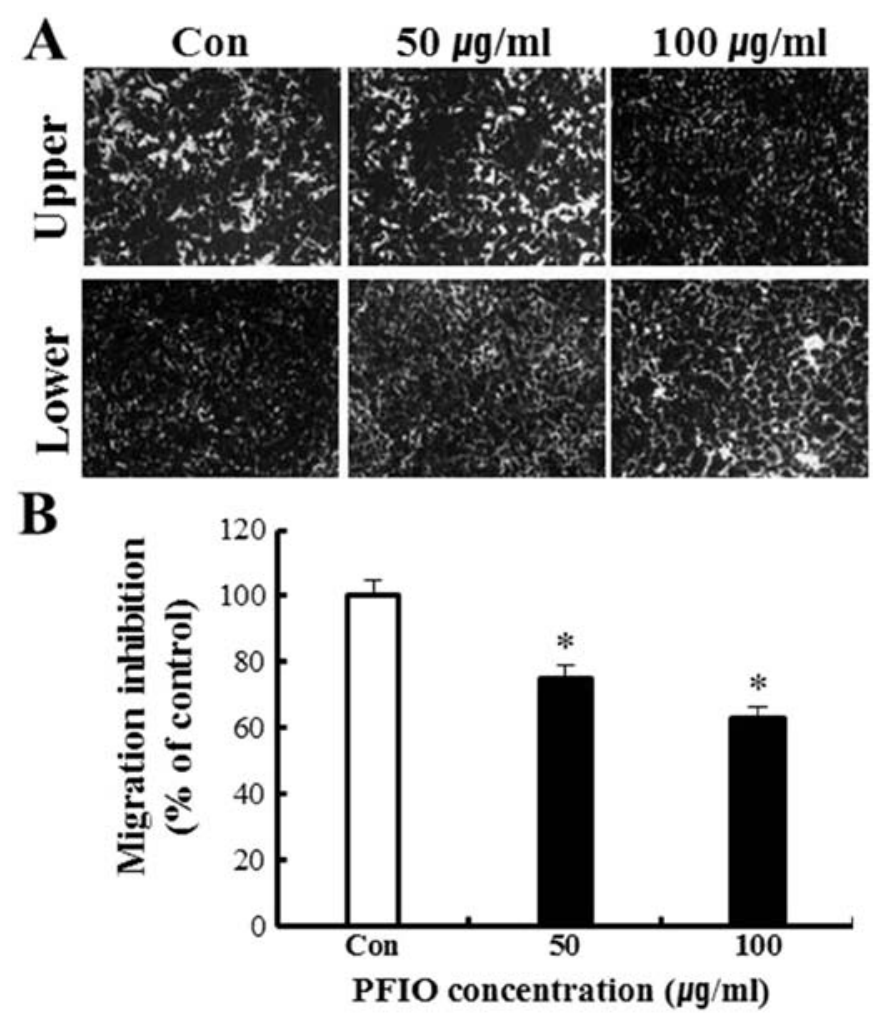

Figure 3. Effect of PFIO on A549 cell migration. A549 cells were treated with various concentrations $(0,50$ and $100 \mu \mathrm{g} / \mathrm{ml})$ of PFIO for $24 \mathrm{~h}$. (A) Cell migration was measured at $24 \mathrm{~h}$ in a transwell chamber with polycarbonate filters (pore size, $8 \mu \mathrm{m}$ ) precoated with gelatin. (B) The migratory ability of A549 cells was quantified by counting the number of migrated cells. Cells were captured using an optical microscope (original magnification, x40). Data are presented as the mean \pm SE of three independent experiments. ${ }^{*} \mathrm{p}<0.05$ indicates a significant difference from controls.

inhibited cell migration by 25 and 37\%, respectively (Fig. 3). As shown in Fig. 4, results of the invasion assay illustrated that untreated A549 cells moved from the upper to the lower chamber, indicating the ability of A549 cells to invade through Matrigel-coated transwell cell culture chambers. However, the addition of PFIO to A549 cells resulted in an inhibitory effect on cellular invasion in a concentration-dependent manner. Data in Fig. 4B indicated that 50 and $100 \mu \mathrm{g} / \mathrm{ml}$ of PFIO significantly inhibited A549 cell invasion by 27 and $46 \%$, respectively. Thus, these results suggested that PFIO effectively reduced cell migration and invasion.

Effect of PFIO on the activities and expression of MMPs in A549 cells. ECM degradation is crucial to cellular invasion, indicating the inevitable involvement of matrix-degrading proteinases (23). Matrix degradation could, however, be suppressed by altering the balance between MMP-2 and TIMP-2 (24). Therefore, the effects of PFIO on protein expression and gelatinolytic activity of MMPs were investigated by gelatin-zymography and western blot analysis under serum starvation condition. As shown in Fig. 5A, MMP-2 and MMP-9 activity was remarkably decreased in A549 cells after PFIO treatment at 25, 50 and $100 \mu \mathrm{g} / \mathrm{ml}$ for $24 \mathrm{~h}$ compared to control. When MMP-2, MMP-9, and TIMP-2 protein expression was determined using western blot analysis, PFIO was 

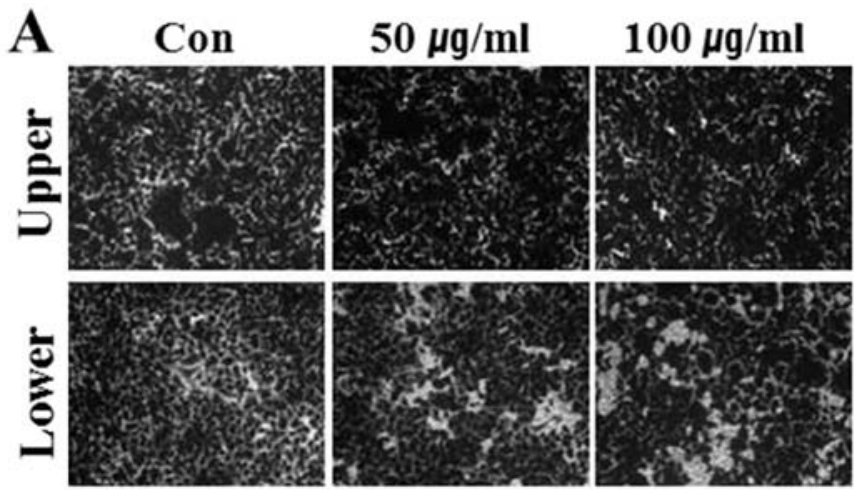

B

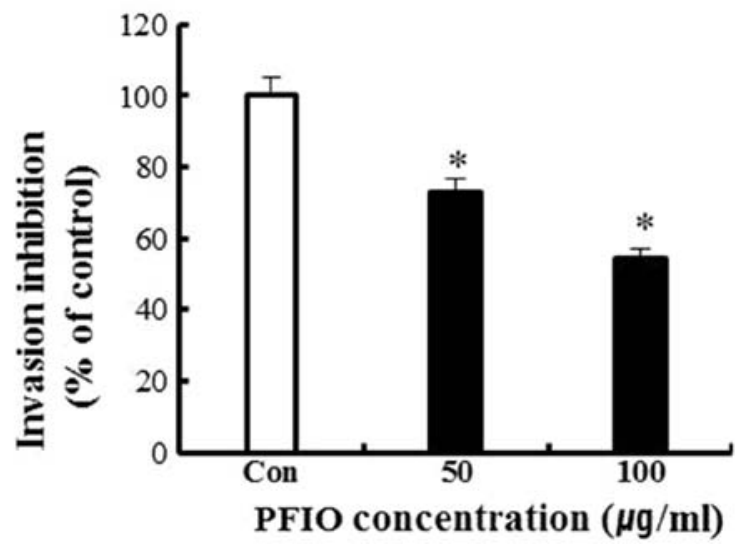

Figure 4. Effect of PFIO on A549 cell invasiveness. A549 cells were treated with various concentrations $(0,50$ and $100 \mu \mathrm{g} / \mathrm{ml})$ of PFIO for $24 \mathrm{~h}$. (A) Cell invasion was measured after $24 \mathrm{~h}$ in a transwell chamber with polycarbonate filters (pore size, $8 \mu \mathrm{m}$ ) precoated with Matrigel. (B) The invasiveness of A549 cells was quantified by counting the number of invaded cells. Cells were captured using an optical microscope (original magnification, $\mathrm{x} 40$ ). Data are presented as the mean \pm SE of three independent experiments. ${ }^{*} \mathrm{p}<0.05$ indicates a significant difference from controls.

found to reduce the expression levels of MMP-2 and MMP-9 but increase that of TIMP-2 in A549 cells (Fig. 5B). Therefore, our results indicated that $\mathrm{PFIO}$ could regulate the expression and activity of MMP-2 and MMP-9.

Effect of PFIO on NF- $\kappa B$ nuclear translocation and COX-2 expression levels in A549 cells. Previous reports have demonstrated that the MMP promoter contains several transcription factor-binding elements, including binding sites for AP-1 and NF- $\mathrm{NB}$. Additionally, nuclear translocation of AP-1 and $\mathrm{NF}-\kappa \mathrm{B}$ in metastatic cancer cells involves the expression of MMPs $(25,26)$. Therefore, $N F-\kappa B$ signal transduction pathway may play an important role in the regulation of MMP-2 and MMP-9 expression. Moreover, COX-2, which is regulated by NF- $\kappa \mathrm{B}$ activation, also affects the expression of MMP-9 in highly metastatic cancer cells (27). To investigate whether PFIO could regulate the NF- $\kappa$ B signaling pathway, A549 cells were treated with the indicated concentrations of PFIO. The translocation of $\mathrm{NF}-\kappa \mathrm{B}$ and $\mathrm{COX}-2$ expression levels were determined by western blot analysis. As shown in Fig. 6, PFIO treatment increased the total cytosolic NF- $\kappa \mathrm{B}$ protein levels in A549 cells was compared to untreated control. In contrast, nuclear levels of NF- $\mathrm{KB}$ protein in A549 cells remarkably decreased after PFIO treatment compared to control. Moreover,

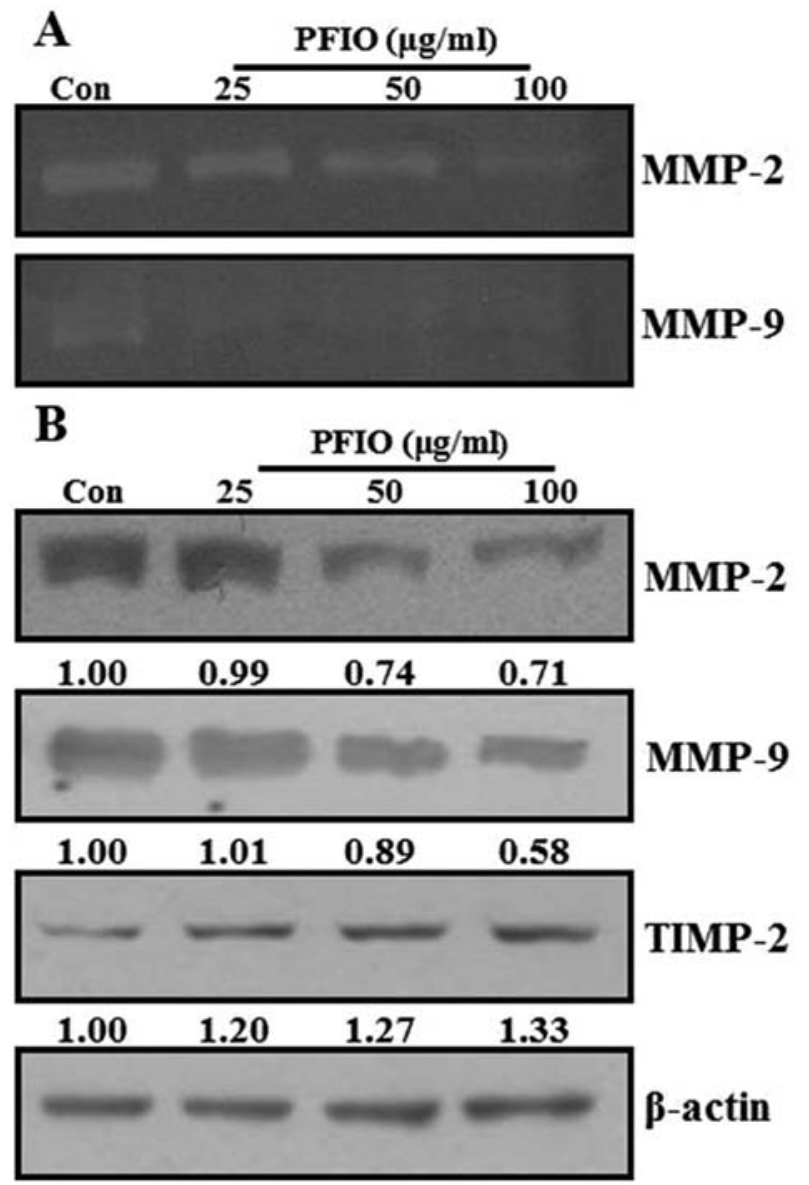

Figure 5. Effect of PFIO on the expression and activities of MMP-2 and MMP-9 in A549 cells. A549 cells were treated with various concentrations of PFIO in serum-free medium for $24 \mathrm{~h}$. (A) Gelatinolytic activities of MMP-2 and MMP-9 were determined by gelatin-zymography. (B) The expression levels of MMP-2, MMP-9 and TIMP-2 were measured by western blot analysis. Equal loading of total proteins in each sample was verified by $\beta$-actin expression.

PFIO suppressed the expression levels of COX-2. These results indicated that $\mathrm{PFIO}$ could regulate $\mathrm{NF}-\kappa \mathrm{B}$ nuclear translocation and COX-2 expression in A549 cancer cells.

Effect of PFIO on MAPKs and AKT signaling pathways in A549 cells. Recent studies reported that MAPKs and PI3K/ AKT signaling pathways are involved in cancer cell migration and invasion $(25,28,29)$. MAPKs and AKT have been demonstrated to be involved in MMP induction in various tumor types (30-33). To examine whether PFIO could regulate MAPKs and AKT signaling pathways in A549 cells, we analyzed the phosphorylation levels of all three MAPKs (ERK, JNK and p38 MAPK) and AKT protein in A549 cells by western blot analysis after PFIO treatment $(25,50$ and $100 \mu \mathrm{g} / \mathrm{ml}$ ) for $24 \mathrm{~h}$. As shown in Fig. 7, PFIO did not affect the expression levels of the three MAPKs and AKT, but it suppressed the phosphorylation of ERK, JNK, p38 MAPK, and AKT compared to controls. In particular, the phosphorylation levels of JNK, p38 MAPK, and AKT were inhibited by the addition of PFIO at 50 and $100 \mu \mathrm{g} / \mathrm{ml}$. These data indicated that PFIO could inhibit the phosphorylation of MAPKs and AKT in A549 cells. 


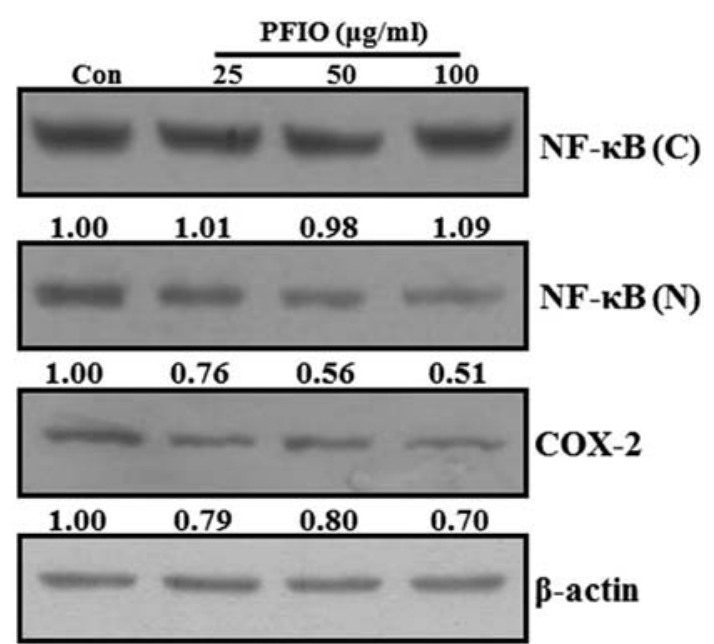

Figure 6. Effect of PFIO on NF-кB translocation and COX-2 expression in A549 cells. A549 cells were treated with various concentrations of PFIO for $24 \mathrm{~h}$. The levels of activated NF- $\mathrm{BB}$ and COX-2 were determined by western blot analysis using a nuclear extraction kit. Equal loading of total proteins in each sample was verified by $\beta$-actin expression.

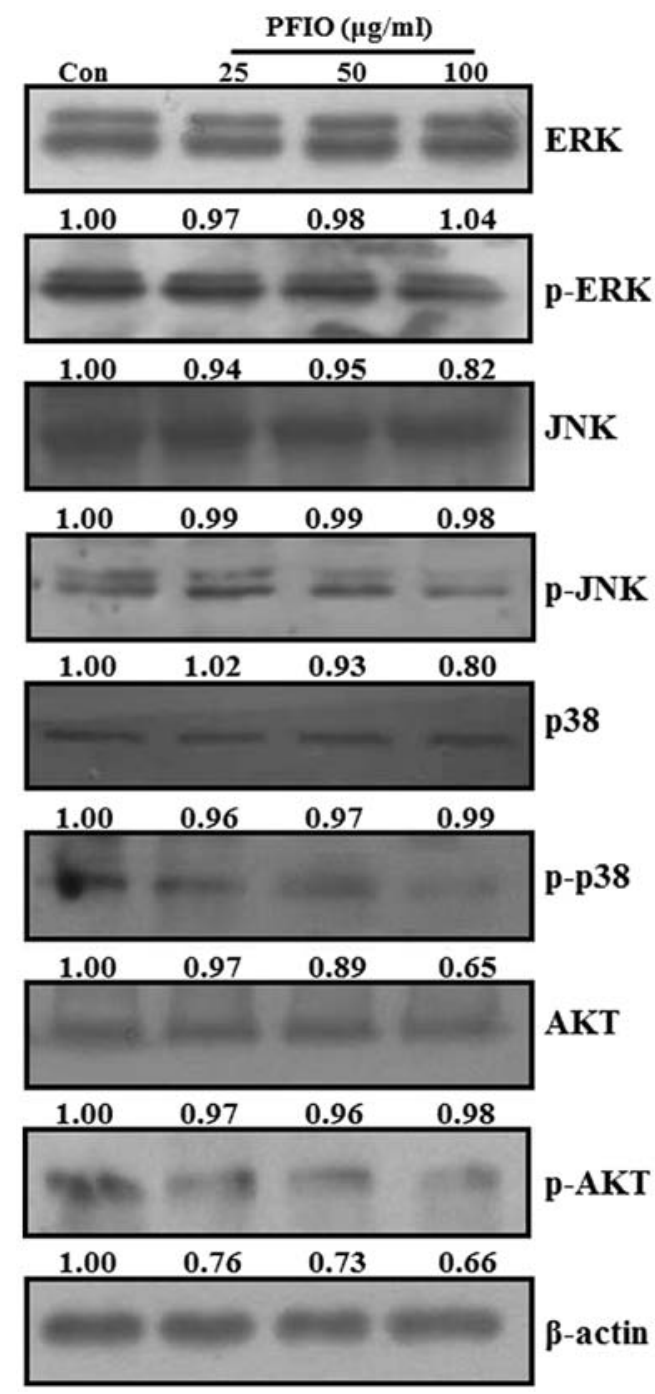

Figure 7. Effect of PFIO on MAPKs and AKT signaling in A549 cells. A549 cells were treated with various concentrations of PFIO for $24 \mathrm{~h}$. The levels of expression and phosphorylation of ERK, JNK, p38 MAPK, and AKT were determined by western blot analysis. Equal loading of total proteins in each sample was verified by $\beta$-actin expression.

\section{Discussion}

Cancer is a major health problem worldwide. In recent years, much attention has been focused on the antitumor properties of natural components for chemotherapeutic applications. Polysaccharide is often implicated with meaningful pharmacological activities (34-39). For instance, polysaccharides extracted from mushrooms such as L.edodes, C. militaris, $H$. erinaceus, and $I$. obliquus are well-known to possess important pharmacological properties. However, the effects of I. obliquus-derived polysaccharides on cancer metastasis in human NSCLC remain unknown. Cancer cell invasion and migration are the important prerequisites of tumor metastasis with invasion of the ECM being a critical step involving the attachment of tumor cells to the ECM. Numerous reports have revealed that the inhibition of MMP expression and/or enzymatic activities could prevent cancer metastasis (26). MMPs have been demonstrated to be major components of the enzyme cascade responsible for the degradation of the ECM and basement membrane proteins (40). Proteolysis of these proteins is part of cell migration, proliferation, differentiation, and tissue remodeling processes related to airway injury. Lung epithelial cells are one of the most important sources of MMPs, such as MMP-1 (55-kDa collagenase), MMP-2 (72-kDa gelatinase A), MMP-7 (28-kDa) and MMP-9 (92-kDa gelatinase B) $(8,25)$. MMP-2 and MMP-9 are involved in the invasive metastatic potential of tumor cells. Furthermore, the expression and activity of COX-2 might modulate those of MMPs (27). MMP-2 and MMP-9 are activated on the cell surface by a multimeric complex with TIMP-1 and TIMP-2, the activation mechanism of which might help elucidate the process of cellular motility, invasion, and migration in cancer metastasis (9). In the present study, we investigated the effects of PFIO on the migration and invasion of the highly metastatic A549 cell line in vitro. Our results from wound healing, migration, and invasion assays demonstrated that PFIO inhibited the migration and invasion of A549 cells (Figs. 2-4). In addition, our findings suggested that PFIO could regulate the expression and activities of MMP-2, MMP-9, and TIMP-2, which facilitated ECM degradation and played important roles in cancer cell migration and invasion (Fig. 5). These results indicated that the anti-metastatic effects of PFIO were associated with the inhibition of enzymatic degradation processes in metastatic A549 cells. Previous reports demonstrated that MMP-2 and MMP-9 promoters consisted of several transcription factor-binding motifs including those for NF- $\kappa \mathrm{B}$. Multiple pathways leading to the activation of NF- $\mathrm{KB}$ binding factors in tumor cells may contribute to MMP-2 and MMP-9 transcription and enhanced invasiveness. In this study, we found that PFIO regulated NF- $\mathrm{KB}$ translocation from the cytosol to the nucleus and COX-2 expression in A549 cells (Fig. 6). Our findings thus implied that PFIO inhibited A549 metastasis by inhibiting NF- $\kappa \mathrm{B}$ translocation and that it suppressed MMP-2 and MMP-9 expression and activities by inhibiting the NF- $\mathrm{KB}$ signaling pathway. Furthermore, PFIO might also regulate other signaling pathways related to the migration and invasion of highly metastatic cancer cells through different mechanisms such as phosphorylation of MAPKs and AKT (Fig. 7). The MAPK signaling pathway was found to promote tumor invasion and metastasis in A549 cells. Our results showed that 
PFIO inhibited the phosphorylation of AKT in A549 cells, suggesting that it might inhibit the AKT signaling pathway. Additionally, PI3K activation reportedly stimulates the downstream target AKT, which is associated with cell invasion (25). The PI3K-AKT pathway is known to play important roles in the cancer cell invasiveness.

In conclusion, as MMPs are very important in tumor metastasis, their gene expression and enzymatic activity are early targets for preventing cancer metastasis. Our study suggested that PFIO inhibited the migration and invasion of highly metastatic A549 cells by inhibition of MMP-2 and MMP-9 activity and expression via downregulation of NF- $\mathrm{B}$, AKT, and/or MAPKs signaling pathways.

\section{Acknowledgements}

This study was supported by the Basic Science Research Program of the National Research Foundation of Korea (NRF) funded by the Korean Ministry of Education (NRF-20110011522).

\section{References}

1. Kanzaki R,Higashiyama M, Fujiwara A, et al: Occult mediastinal lymph node metastasis in NSCLC patients diagnosed as clinical N0-1 by preoperative integrated FDG-PET/CT and CT: risk factors, pattern, and histopathological study. Lung Cancer 71: $333-337,2011$

2. Olmez I, Donahue BR, Butler JS, Huang Y, Rubin P and Xu Y: Clinical outcomes in extracranial tumor sites and unusual toxicities with concurrent whole brain radiation (WBRT) and Erlotinib treatment in patients with non-small cell lung cancer (NSCLC) with brain metastasis. Lung Cancer 70: 174-179, 2010.

3. Spizzo G, Seeber A and Mitterer M: Routine use of pamidronate in NSCLC patients with bone metastasis: results from a retrospective analysis. Anticancer Res 29: 5245-5249, 2009.

4. Fidler IJ, Kim SJ and Langley RR: The role of the organ microenvironment in the biology and therapy of cancer metastasis. J Cell Biochem 101: 927-936, 2007.

5. Shiraga M, Yano S, Yamamoto A, et al: Organ heterogeneity of host-derived matrix metalloproteinase expression and its involvement in multiple-organ metastasis by lung cancer cell lines. Cancer Res 62: 5967-5973, 2002.

6. Ciborowski P and Finn OJ: Non-glycosylated tandem repeats of MUC1 facilitate attachment of breast tumor cells to normal human lung tissue and immobilized extracellular matrix proteins (ECM) in vitro: potential role in metastasis. Clin Exp Metastasis 19: 339-345, 2002.

7. Santos MC, de Souza AP, Gerlach RF, Trevilatto PC, ScarelCaminaga RM and Line SR: Inhibition of human pulpal gelatinases (MMP-2 and MMP-9) by zinc oxide cements. J Oral Rehabil 31: 660-664, 2004.

8. Corbel M, Boichot E and Lagente V: Role of gelatinases MMP-2 and MMP-9 in tissue remodeling following acute lung injury. Brazilian J Med Biol Res 33: 749-754, 2000.

9. Cheng Y, Dong Q, Sun LR, Yang CM and Jiang BX: Correlation between expression of MMP-2, MMP-9, TIMP-2, TIMP-1 and metastasis of neuroblastoma. Zhonghua Zhong Liu Za Zhi 27 164-166, 2005 (In Chinese).

10. Chaudhry K, Rogers R, Guo M, et al: Matrix metalloproteinase-9 (MMP-9) expression and extracellular signal-regulated kinase 1 and 2 (ERK1/2) activation in exercise-reduced neuronal apoptosis after stroke. Neurosci Lett 474: 109-114, 2010.

11. Hu YB, Zong YR, Feng DY, Jin ZY, Jiang HY and Peng JW: p38/ERK signal pathways regulating the expression of type I collagen and activity of MMP-2 in TGF-beta1-stimulated HLF-02 cells. Zhonghua Lao Dong Wei Sheng Zhi Ye Bing Za Zhi 24: 77-80, 2006 (In Chinese).

12. Cheng JC, Chou CH, Kuo ML and Hsieh CY: Radiationenhanced hepatocellular carcinoma cell invasion with MMP-9 expression through PI3K/Akt/NF-kappaB signal transduction pathway. Oncogene 25: 7009-7018, 2006.
13. Cui D, Zhang X and Fu Y: Expressions of COX-2 and MMP-2 in nasopharyngeal carcinoma and the their relationship with lymph node metastasis]. Lin Chung Er Bi Yan Hou Tou Jing Wai Ke Za Zhi 22: 692-694, 2008 (In Chinese).

14. Dixon DA, Tolley ND, Bemis-Standoli K, et al: Expression of COX-2 in platelet-monocyte interactions occurs via combinatorial regulation involving adhesion and cytokine signaling. J Clin Invest 116: 2727-2738, 2006.

15. Shifflett DE, Jones SL, Moeser AJ and Blikslager AT: Mitogenactivated protein kinases regulate $\mathrm{COX}-2$ and mucosal recovery in ischemic-injured porcine ileum. Am J Physiol Gastrointest Liver Physiol 286: G906-G913, 2004.

16. Lee KR, Lee JS, Kim YR, Song IG and Hong EK: Polysaccharide from Inonotus obliquus inhibits migration and invasion in B16-F10 cells by suppressing MMP-2 and MMP-9 via downregulation of NF-kappaB signaling pathway. Oncol Rep 31: 2447-2453, 2014

17. Yun JS, Pahk JW, Lee JS, Shin WC, Lee SY and Hong EK: Inonotus obliquus protects against oxidative stress-induced apoptosis and premature senescence. Mol Cells 31: 423-429, 2011.

18. Won DP, Lee JS, Kwon DS, Lee KE, Shin WC and Hong EK: Immunostimulating activity by polysaccharides isolated from fruiting body of Inonotus obliquus. Mol Cells 31: 165-173, 2011.

19. Lee JS, Kwon JS, Won DP, et al: Study of macrophage activation and structural characteristics of purified polysaccharide from the fruiting body of Cordyceps militaris. J Microbiol Biotechnol 20: 1053-1060, 2010.

20. Lee JS and Hong EK: Hericium erinaceus enhances doxorubicininduced apoptosis in human hepatocellular carcinoma cells. Cancer Lett 297: 144-154, 2010.

21. Rodriguez LG, Wu X and Guan JL: Wound-healing assay. Methods Mol Biol 294: 23-29, 2005.

22. Toth M, Sohail A and Fridman R: Assessment of gelatinases (MMP-2 and MMP-9) by gelatin zymography. Methods Mol Biol 878: 121-135, 2012.

23. Artym VV, Yamada KM and Mueller SC: ECM degradation assays for analyzing local cell invasion. Methods Mol Biol 522: 211-219, 2009.

24. Powell K: ECM signals ECM degradation. J Cell Biol 172: 642, 2006.

25. Lee YC, Lin HH, Hsu CH, Wang CJ, Chiang TA and Chen JH: Inhibitory effects of andrographolide on migration and invasion in human non-small cell lung cancer A549 cells via downregulation of PI3K/Akt signaling pathway. Eur J Pharmacol 632: 23-32, 2010.

26. Philip S, Bulbule A and Kundu GC: Matrix metalloproteinase-2: mechanism and regulation of NF-kappaB-mediated activation and its role in cell motility and ECM-invasion. Glycoconj J 21: 429-441, 2004.

27. Callejas NA, Casado M, Diaz-Guerra MJ, Bosca L and Martin-Sanz P: Expression of cyclooxygenase-2 promotes the release of matrix metalloproteinase-2 and -9 in fetal rat hepatocytes. Hepatology 33: 860-867, 2001.

28. Wu KC, Yang ST, Hsia TC, et al: Suppression of cell invasion and migration by propofol are involved in down-regulating matrix metalloproteinase-2 and p38 MAPK signaling in A549 human lung adenocarcinoma epithelial cells. Anticancer Res 32: 4833-4842, 2012.

29. Ni L, Feng Y, Wan H, et al: Angiotensin-(1-7) inhibits the migration and invasion of A549 human lung adenocarcinoma cells through inactivation of the PI3K/Akt and MAPK signaling pathways. Oncol Rep 27: 783-790, 2012.

30. Lu CC, Yang JS, Chiang JH, et al: Inhibition of invasion and migration by newly synthesized quinazolinone MJ-29 in human oral cancer CAL 27 cells through suppression of MMP-2/9 expression and combined down-regulation of MAPK and AKT signaling. Anticancer Res 32: 2895-2903, 2012.

31. Jung JS, Jung K, Kim DH and Kim HS: Selective inhibition of MMP-9 gene expression by mangiferin in PMA-stimulated human astroglioma cells: involvement of PI3K/Akt and MAPK signaling pathways. Pharmacol Res 66: 95-103, 2012.

32. Kang MH, Oh SC, Lee HJ, et al: Metastatic function of BMP-2 in gastric cancer cells: the role of PI3K/AKT, MAPK, the NF-kappaB pathway, and MMP-9 expression. Exp Cell Res 317: 1746-1762, 2011.

33. Cho SJ, Chae MJ, Shin BK, Kim HK and Kim A: Akt- and MAPK-mediated activation and secretion of MMP-9 into stroma in breast cancer cells upon heregulin treatment. Mol Med Rep 1: 83-88, 2008. 
34. Zhang S, Nie S, Huang D, Huang J, Wang Y and Xie M: Polysaccharide from Ganoderma atrum evokes antitumor activity via Toll-like receptor 4-mediated NF-kappaB and mitogenactivated protein kinase signaling pathways. J Agric Food Chem 61: 3676-3682, 2013

35. Cardozo FT, Larsen IV, Carballo EV, et al: In vivo anti-herpes simplex virus activity of a sulfated derivative of Agaricus brasiliensis mycelial polysaccharide. Antimicrob Agents Chemother 57: 2541-2549, 2013.

36. Liu Y, Li Y, Yang W, Zhang L and Cao G: Anti-hepatoma activity in mice of a polysaccharide from the rhizome of Anemone raddeana. Int J Biol Macromol 50: 632-636, 2012.

37. Lee JS and Hong EK: Agaricus blazei Murill enhances doxorubicin-induced apoptosis in human hepatocellular carcinoma cells by NFkappaB-mediated increase of intracellular doxorubicin accumulation. Int J Oncol 38: 401-408, 2011.
38. Sinha S, Nosalóva G, Bandyopadhyay SS, Fleskova D and Ray B: In vivo anti-tussive activity and structural features of a polysaccharide fraction from water extracted Withania somnifera. J Ethnopharmacol 134: 510-513, 2011.

39. Li H, Lu X, Zhang S, Lu M and Liu H: Anti-inflammatory activity of polysaccharide from Pholiota nameko. Biochemistry Biokhimiia 73: 669-675, 2008.

40. Baricos WH, Cortez SL, el-Dahr SS and Schnaper HW: ECM degradation by cultured human mesangial cells is mediated by a PA/plasmin/MMP-2 cascade. Kidney Int 47: 1039-1047, 1995. 